\title{
Business Intelligence in Educational Institutions
}

\author{
Agustín León-Barranco, Susana N. Saucedo-Lozada, Iselt Y. Avendaño-Jimenez, \\ Ricardo Martínez-Leyva, Luis A. Carcaño-Rivera \\ Universidad del Valle de México, Coordinación de Ingeniería, Puebla, Pue., México \\ agustinleonbeinaoep.mx, snsl_nicol@hotmail.com, \\ iselt.avendanoji@my.uvm.edu.mx, ricardomtzleyva@naatbot.com, \\ luis.carcanori@uvmnet.edu
}

\begin{abstract}
Thanks to the Information and Communication Technology (ICT), nowadays it is possible to access to a lot more quality information and faster too, but analyzing such an amount of information it is not a simple task for a human. However is in charge with their management suffers needs to make decisions based on their experience. Knowledge becomes a competitive advantage in the fundamental tool makers of educational management to make decisions that best promote the organization. The integration of advances in ICT, data mining and business intelligence is a field of extensive exploration to bring more intelligence to business, and in particular educational institutions.
\end{abstract}

Keywords: Business intelligence, big data, decision making, data mining, educational organizations, educational management.

\section{Introduction}

With the modern conditions of competence, making decisions has become a very difficult and risky task for directors these days. It is true that thanks to the technologies of information and communication technology (ICT) it is now possible to access to much more information, higher quality and faster, but it is also true that analyzing such amounts of information is no longer a simple task for a human. Management of information on business organizations is a key tool in surviving the dynamic, global market from nowadays. This document presents an educational management based on business intelligence whose purpose is helping in the "decision making". Taking better decisions in pro of education could increase the quality of educational institutions which gives them more competitiveness in this fierce market. Learning to compete with this information is crucial for decision making, growth and management of educational organizations. The most competitive countries are those that are making the best use of ICT, those that dominate and productively apply the knowledge. Attracting and retaining more students and resources, for instances, has become the main driver of the management of university governments. 


\section{Proposed Solution}

This work is focused on solving problems in the decision making for an educational institution by using ICT and other disciplines such as data mining and business intelligence. The way to do it is by means of an online system connected to databases which helps directors to make better decisions about the school.

Today, integrating advances in ICT, data mining and business intelligence is a great opportunity for academic competitiveness, in the future it will be a necessity to bring more intelligence to educational institutions. On the one hand, data mining encompasses a range of techniques to achieve the efficient operation of the data, by extracting actionable knowledge that is implicit in the databases, knowledge with which it is possible to solve problems of prediction, classification and segmentation. On the other hand, business intelligence encompasses understanding the actual operation of the organization by anticipating future problems by means of knowledge obtained with data mining.

\section{Main Contribution}

The purpose of this document is to show an educational management based on business intelligence to aid decision making in a university institution.

Educational management based on business intelligence covers not only decision-making in top management, but also other levels as academic direction and marketing. There are four items on which this research on management is focused: student monitoring, teacher follow-performing, loans and market opportunity.

\section{$4 \quad$ Project Justification}

Educational institutions are organizations [1], since there is a structure (director, deputy director, coordinators, teachers, etc.), there are operation and communication, there are goals and objectives, etc. Note that the educational institution is an organization of difficult management [2], because the core of it is the people, and sometimes, the interests are not the same for everyone. Making a clever tracking of each entity is not an easy task but it is necessary to make decisions that best suit the organization.

This new information era demands changing the paradigm of educational management to improve competitiveness and development of education, with the development of information technologies and new algorithms for treating information directors are potentially capable of processing and analyze vast amounts of information to be taken into account when making a decision. Hence lays the importance of proposing a new educational management based on business intelligence to improve decision-making at the University Institution. 


\section{Theoretical Background}

The educational administration requires, besides the effective and efficient management of human and material resources, information management to provide a strategic and forward-looking vision.

Large amounts of information generated in educational institutions sometimes have hidden knowledge difficult to be seen for one person, but thanks to the development of data mining and business intelligence, it is possible to exploit their progress to troubleshoot educational management, one of these advances is the ability to extract knowledge from large databases to help managers make better decisions that allow growth and strengthening of educational organization.

"It is possible to extract useful knowledge from huge amounts of existing databases of educational institution to aid decision making on issues of educational management information."

Business Intelligence, what does it means?: It refers to the development of strategies and relevant aspects that focus on the creation and management of knowledge. It is closely related to the extraction of information from databases on a large scale.

Business Intelligence encompasses understanding the actual operation of the company anticipating future problems by using information obtained from the Data Mining, it is a powerful tool for academic intervention. Use a combination of explicit knowledge and sophisticated analytical skills to uncover secret information patterns (using pattern recognition technology as well as mathematical and statistical techniques); these patterns are the basis of predictive models that allow analysts to produce new observations of existing data.

Technology of information and communication: ICTs are comprised of four key sectors: communications, information infrastructure or hardware, software (packaged and custom) and services (support and professional implementation and outsourcing).

Their purpose is to help maximize the economic potential of individuals and companies and at the same time increasing their standard of living beyond the intrinsic potential of their own resources and technological capabilities, regardless of their economic fluctuations.

The Web 2.0 gave the user the opportunity and freedom to become a creator and editor of dynamic pages open content, enabling collaboration and social appropriation of the Internet. [3] The incorporation of products, tools, services, applications, etc., are enabling the creation of groups, communities and social networks to create, manage and share information, spaces and events by growing the personal, professional, social, political, economic, etc.

The development of ICT allowed the world to become smaller and competition among nations unaware of borders. For Mexico this may be the opportunity to attract investment, or conversely, to lose most attractive nations. Leaning on ICT is a key to improving rates of productivity and competitiveness of the country condition.

There is a high dependency on the competitiveness of countries with their competitiveness in information technology, if you want to measure the competi- 
tiveness of countries this should be measured with the competitiveness they have in information technology.

Competitiveness is an objective on which the Mexican government should work, mainly promoting the development and diffusion of Information Technology and Communication sector. Therefore, it is important to begin to build competitive economy in the country offering quality goods and services at accessible prices, creating favorable conditions for the development of business conditions; it is important to generate the necessary human capital to contribute to the development of service industry information technology and make it internationally competitive and ensure its growth in the long term.

New environment of education systems in Mexico: Advances in science and technology have led to profound and significant changes in the economic and productive processes, social organization and the conception of the world and life. "An organization never exists for itself. She meets social functions that correspond to expectations of the society around it".

All organizations are forced to review both their goals and missions they seek to fulfill in society, and their modes of organizing and operations to meet their goals. The school is one of the few social institutions whose importance makes it the center of analysis and questioning from within and from outside it. Those charged with its management are faced with a task of such complexity they never before had, which requires a high level of professional competence[4].

Specifically it is considered that the director of the organization must show his ability as a leader and innovator, know how to apply the changes to practice, determine the extent of change, the ability to support and encourage the skills necessary to foster an organization that assumes learning [5].

Education and ICT, the way to connect two worlds: At the school level relevant factors include: meaningful and understood by all goals, attention to daily academic performance, coordination between programs and between school and parents, faculty development and organization of the school to support learning for all.

Strategies and resources that appear decisive in resolving problems are mainly: communication and participation, knowledge of the school system and external resources to school, cognitive flexibility, etc.

We can also appreciate the influence and impact that ICT industry has on the educational competitiveness, same that is reflected in the detonation of new production and development capabilities; Likewise, it has been observed that, unfortunately, Mexico still has a big job ahead to provide its sectors the necessary ICT enabling it to raise its competitiveness in their industries.

The influence of ICT in the education sector has an enormous responsibility because they are center of knowledge. In the contemporary world, universities must play a leading role in the progress of science and technology and dilute doubts about his ability to adapt to new social contexts and offer products that meet the needs of so-called knowledge society.

The quality of education is influenced by factors such as wealth of a society or national education policy objectives, standards, and methods of teacher recruitment. Many institutions have implemented analysis to improve enrollment management. The "actionable intelligence" is Technological achievements in communications have 
revolutionized the spread of information. ICT offers us the opportunity to perform multiple tasks simultaneously knocking our barriers of time and space. Thanks to advances in communications technology people are increasingly interconnected.

Organizations are facing new challenges because, although they have greater access to valuable information, they do not know how to extract value or knowledge of them to make better decisions.

As never before in history, companies are now able to store anything digitally, but as they can generate huge amounts of information, it also decreases the percentage of data that businesses can process. The term Big Data applies to information that cannot be processed or analyzed using traditional tools or processes [6].

Big Data, the big amount of data: It is the term used today to describe the set of processes, technologies and business models that are based on capturing the value contained in the data itself. This can be achieved both through improved efficiency through data analysis, and by the appearance of new business models supposing an engine of growth. There is much talk of the technological aspect, but keep in mind that it is critical to find ways to give value to the data to create new business models or help existing ones.

Big Data is no longer a promise or a trend. Big Data is here and is causing profound changes in various industries. The analysis of information in large volumes, from various sources, at high speed and with unprecedented flexibility can be a differentiating factor for those who choose to adopt it [7].

With many institutions launching a Big Data strategy, the ability of a competitor to take your best customers is a growing threat. While internal organizational data represent a clear competitive advantage, unstructured knowledge available online, via mobile channels and social networks, is equally valuable. "Innovation in technology is a huge differentiator in today's financial services market"[8].

Operations research, something really needed: Also known as management science is a scientific approach based on mathematical models for decision-making, example: mathematically representing real situations to make better decisions.

Operations Research (OR) models are designed to "optimize" objective criteria specified subject to a set of constraints; the quality of the resulting solution depends on the accuracy with which the model represents the real system. Operations research is both an art and a science; the art of describing and modeling the problem, and science to solve the model using precise mathematical algorithms.

Data Analysis: Data analysis is the process in which the raw data are sorted and organized to be used in methods that help to explain the past and predict the future [9]. Requires skills in three areas: computer science, artificial intelligence (machine learning, data mining, etc.), and finally statistics and mathematics.

Academic Analysis: This analysis focuses on improving the admission and retention of students and related operational performance through the implementation of executive dashboards that provide points of leverage to improve performance and accountability.

In many ways, the analytic action is like a heterogeneous mix of options, all aligned with corporate objectives and strategies. To really put the action in analysis, higher education institutions need leaders committed to organizational ca- 
pacity to measure and improve performance and change the organizational culture and behavior[10].

Data mining: is a powerful tool for academic intervention. Use a combination of explicit knowledge and sophisticated analytical skills to uncover secret information patterns (using pattern recognition technology as well as mathematical and statistical techniques); of these patterns the basis of predictive models that allow analysts to produce new observations of existing data emerge [11].

Social Business: The pioneers in adopting social business are registering the positive benefits and opportunities promised by social technologies. Along with other key trends (portability, cloud and big data), the social business begins to offer some suggestions of interesting value.

Bet on social business requires serious rethinking business results and the social nature of people, fusing technology, culture and values. Merging social media (social media), media work, social listening, social work, social intelligence and other social technology companies improve their business models maximizing efficiency and creating value. Additional benefits also impact other building blocks of the business model, such as Value Propositions and Customer Relationship [12].

\section{Results}

The purpose of this research is to establish the basis of an educational management based on business intelligence to help monitor the quality of education. The integration of advances in science and technology with the knowledge and demands for quality in education will be materialized in a digital platform to support decision-making in educational institutions.

The development of ICT today allow us to process large amounts of data and extract knowledge in real time, data mining has the appropriate set of techniques for efficient use of data by extracting actionable knowledge that is implicit in databases, knowledge with which it is possible to solve problems of prediction, classification and segmentation. The educational administration requires, besides the effective and efficient management of human and material resources, information management to provide a strategic and forward-looking vision.

On the other hand, business intelligence provides an understanding of the current operation in anticipation of future problems from knowledge obtained by data mining.

Education systems are in new social contexts with permanent and faster changes where control or reduce environmental uncertainty has become an impossible task, it is time to invest in a new management methodology that exploits the richness and benefits of the information business, a methodology supported on knowledge, a methodology for smarter business.

The problems encountered are becoming more complicated day by day and require complex thinking to build strategies to address the unpredictable, the random and qualitative, is no longer enough simply thought that establishes programs to control what is certain, calculable and measurable . 
Management is one of the most important human activities, has been essential to ensure coordination of individual efforts. Management is the process of designing and maintaining an environment in which, working in groups, individuals efficiently meet specific objectives.

Science produces knowledge, while technology makes use of them. The term technology refers to the sum total of knowledge that we have about how to do things.

In the future, the planning / institutional management and associated knowledge flows can be seamlessly integrated, including strategic planning, expeditionary strategy execution, budgeting, reinventing processes and continuous improvement, accreditation, academic and critic programmable planning, and individual performance management.

Goals, objectives and performance can be measured, monitored, managed and aligned in all planning processes. The ability of colleges and universities to continue to provide leadership in knowledge is at risk. Information overload, increased competition, costly investments in technologies, increasing energy costs and benefits, heavier administrative requirements, lower net revenue per student (through initiatives to broaden participation), and a number of other forces are at fault. One facet of the solution is the use of knowledge services (and supporting technologies and systems) that offer higher value of investments in every area of operations of the institution. But colleges and universities must do so in a sustainable way, providing a transition from legacy to more accessible and flexible serviceoriented and component-based approaches and aggregation of knowledge systems[13].

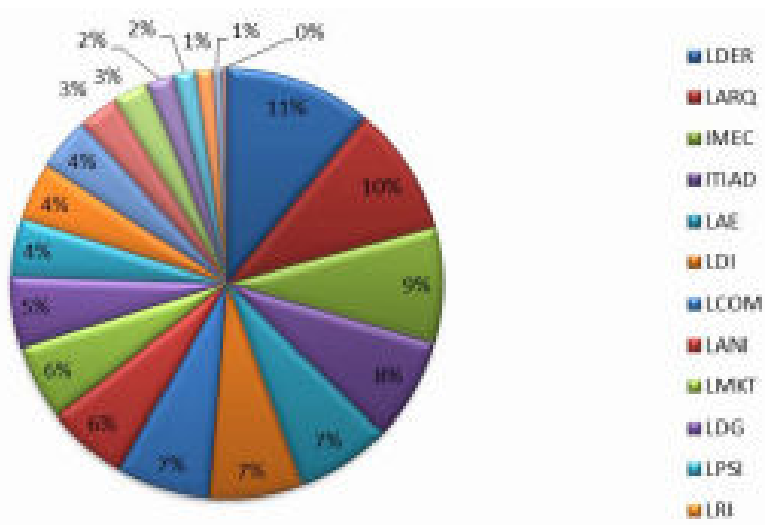

Fig. 1. Desertion per career

A study was developed within an educational institution of higher level, for reasons of confidentiality of information, can not disclose the name; in order to identify in real time the amount of students defection, providing more reliable information to managers, for better decision making.

The study was conducted in 2013, covering two semesters of study. Based on an exhaustive study of low educational institution of higher level conducted in 2013, can be seen in Figure 1 race predominates at low is LDER with $11 \%$, following the LARQ with $10 \%$ and IMEC with $9 \%$. 
Table 1. Selected careers for this research study

\begin{tabular}{ll}
\hline NAME & CAREER \\
\hline LDER & Law \\
LARQ & Architecture \\
IMEC & Mecatronics \\
ITIAD & Digital Animation \\
LAE & Administration \\
LDI & Industrial Design \\
LCOM & Communication \\
LANI & International Business \\
LMKT & Marketing \\
LDG & Graphic Design \\
LPSI & Psychology \\
LRI & International Relations \\
\hline
\end{tabular}

It was also studied and analyzed the reason for desertion, for instance, the economic reason shows $17.8 \%, 16.4 \%$ of the casualties were due to a change of Institution of students, while $12.8 \%$ made only one change of campus. Through the analysis we can also note that a $5.4 \%$ casualties were due to low student achievement, and $1 \%$ by dissatisfaction with academic and administrative services. Different grounds of the 298 students killed in 2013 are shown in Figure 2.

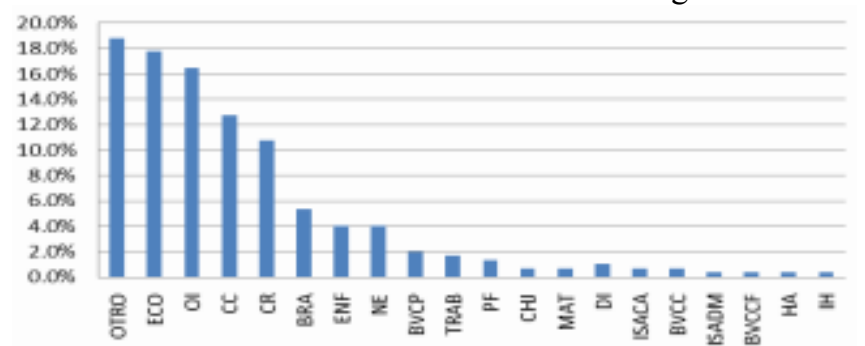

Fig. 2. Reason for desertion

Based on the analysis of the study, is also identified the month with bigger desertion: August with 22\%, January with $15 \%$ and September with $14 \%$. In months like March, May, November, December just between 2 and 3\% of students desertion. In Figure 3 is shown in detail.

In Figure 4, we can also observe that a large percentage found that $18 \%$ of students, do not have the date they entered the institution therefore you cannot get actual data.

Thanks to these studies and analysis we can see the importance of real information within an educational institution, these analytical models give us key tools to get a clearer view of the problem to be solved, having real knowledge bases, giving us to attack the main variables.

Finally, the duration at the institution before defection was analyzed. In Figure 4, the percentages where we can observe that $44.3 \%$ of the students dropped out 
before the first year. $20.5 \%$ of them defect in the first year of study, $8.1 \%$ in its second year, and only $1 \%$ of students dropped out after six years.



Fig. 3. Desertion per month

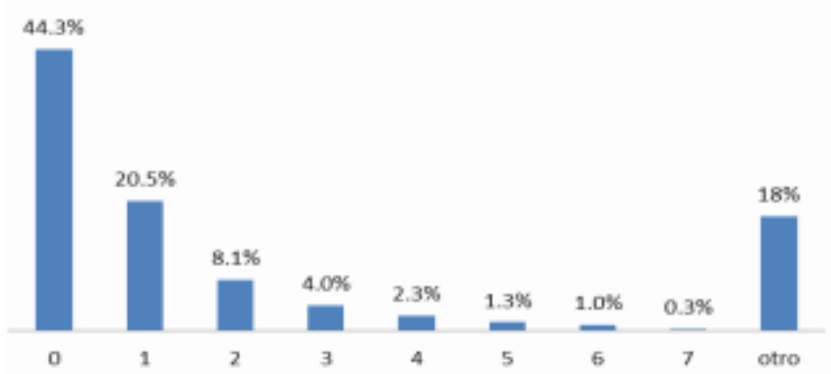

Fig. 4. Time within institution before desertion

As shown in the different graphics, the institution does not have any real information and there are significant percentages that do not have the correct or specified data.

\section{Conclusions}

The Analytical models for analyzing people can provide better decision-making and more efficient ones. That is why this work is focused on developing a methodology for educational management based on business intelligence to aid decision making.

In this context, all human organizations are affected because they depend largely on its adaptation to the environment they operate in. Education systems are no exception to this general situation, like other organizations, the acceleration of change 
in all spheres of social life requires rethinking both their goals and in their modes of organization and conduction.

Make better decisions in favor of education certainly impact the quality of educational institutions which will give them greater competitiveness in an increasingly vicious market. The most competitive countries are those that are making the best use of ICT, which dominate and productively apply knowledge. In places like Puebla with a high number of schools of higher level, knowledge becomes a competitive advantage in the fundamental tool of the makers of educational management to make decisions that best promote the organization.

IT leaders may soon be academic and student affairs important collaborators. They can help answer accountability. through academic analysis, which is emerging as a new tool for a new era. "In the information age, one of the most influential institutions is education".

With the enterprise-wide systems that generate huge amounts of data, data warehouses aggregates different types of data and processing capacity, classifies and surfaces, academic analysis is becoming a new tool that can tackle what appears insoluble.

Richer data sets, new ways to extract and organize data, more sophisticated predictive models, and further research will drive the evolution of analytics. As the practice of analytical gets refined, colleges and universities can place more and better information in the hands of more people, enabling better decision-making. As a result, it is necessary that staff have over traditional IT skills.

The universities respond to the demand for greater accountability in higher education, the emerging practice of academic analytics likely to become a new, highly useful tool for a new, highly demanding era [13].

A key ingredient of analytic action is incorporating labor requirements in educational programs. Intervention strategies are based on powerful analytical steps to make a difference in college readiness and success for underserved students. Preparedness, awareness, financial and institutional responsibility for student success.

The world of information and knowledge is so diverse and abundant that it is vital to mastering the fundamentals associated with a skilled management methods to collect, find, interpret, analyze and recreate potentially useful knowledge required. Managing information in business organizations is, today, a key tool for survival in a changing and dynamic global market.

\section{References}

1. Carregal, M.: Planificación Estratégica.

http://www.youtube.com/watch?v=fsnh500g_cy\&safe=active

2. Cassasus, J.: Problemas de la gestión educativa en América Latina (la tensión entre los paradigmas de tipo A y el tipo B). UNESCO (2000)

3. García, L.: ¿Web 2.0 vs Web 1.0?. BENED (2007)

4. Pozner, P.: Diez módulos destinados a los responsables de los procesos de transformación educativa. IIPE - UNESCO Sede Regional Buenos Aires-Argentina (2000) 
5. Louis, K.S. \& Kruse, S.D.: Professionalism and community: Perspectives on reforming urban schools. Thousand Oaks, CA: Corwin Press (1995)

6. Zikopoulos, P., Eaton, C., de Roos, D., Deutsch, T. \& Lapis, G.: Understanding Big Data: Analytics for Enterprice Class Hadoop and Streaming Data. IBM Corporation. Mc-Graw Hill (2012)

7. Benefitting from Big Data Leveraging Unstructured Data Capabilities for Competitive Advantage, http://www. insightdata.com.au/?p=1738

8. Cuesta, H.: Practical Data Analysis: Transform, model, and visualize your data through hands-on projects, developed in open source tools. Packt Publishing. Birmingham, UK (2013)

9. Norris, D., Baer, L., Leonard, J., Pugliese, L., Lefrere, P.: Framing Action Analytics and Putting Them to Work. EDUCAUSE Review 43(1), 1-10 (2008)

10. Siraj, F. and Ali, A. M.: Mining Enrollment Data Using Descriptive and Predictive Approaches. In: Knowledge-Oriented Applications in Data Mining, pp. 53-71 (2011)

11. Kiron, D., Palmer, D., Phillips, A.N., Kruschwitz, N.: Social Business: What Are Companies Really Doing?. MIT Sloan management review 53(4), 1-32 (2012)

12. Norris, D. M. and Baer, L. L.: Building Organizational Capacity for Analytics. EDUCAUSE 1-58 (2013)

13. Campbell, J. P., DeBlois, P. B. and Oblinger, D. G.: Academic Analytics a new tool for a new era, http://www. educause. edu/library/resources/buildingorganizationalcapacity-analytics 